\title{
A 5-Year Review of the Presentation and Management of Urolithiasis in a Nigerian Teaching Hospital
}

\author{
Olufunmilade Omisanjo ${ }^{1,2, *}$, Muftau Bioku², Omolara Williams ${ }^{1,2}$, Olufemi Akinola ${ }^{2}$, \\ Fatai Balogun $^{2}$, Stephen Ikuerowo ${ }^{1,2}$ \\ ${ }^{1}$ Department of Surgery, Lagos State University College of Medicine, Ikeja, Lagos, Nigeria \\ ${ }^{2}$ Department of Surgery, Lagos State University Teaching Hospital, Ikeja, Lagos, Nigeria
}

Email address:

sanjofunmi@yahoo.com (O. Omisanjo)

${ }^{*}$ Corresponding author

\section{To cite this article:}

Olufunmilade Omisanjo, Muftau Bioku, Omolara Williams, Olufemi Akinola, Fatai Balogun, Stephen Ikuerowo. A 5-Year Review of the Presentation and Management of Urolithiasis in a Nigerian Teaching Hospital. Journal of Surgery. Vol. 7, No. 5, 2019 , pp. $143-147$. doi: $10.11648 /$ j.js.20190705.16

Received: May 23, 2019; Accepted: August 26, 2019; Published: September 16, 2019

\begin{abstract}
Introduction: Urolithiasis has afflicted humans since centuries dating back to $4000 \mathrm{BC}$, with the disease prevalence differing in various parts of the world. Contrary to earlier studies that depicted urinary stone disease as rare in Nigeria, recent reports have shown an increasing incidence. We aim to document the pattern and management of urinary tract calculi seen at the Lagos State University Teaching Hospital, Ikeja, Nigeria. Patients and Methods: We retrospectively reviewed the cases of urolithiasis managed at Lagos State University Teaching Hospital, Ikeja, Nigeria between January 2012 and December 2016. Variables analyzed were patients' age, gender, presenting symptoms, investigations and modalities of treatment. Results: The clinical records of a total of seventy-six patients treated for urinary stone disease within the 5-year study period were available for review. The ages of the patients ranged from 2 years to 84 years with a mean age of $49.13 \pm 16.27$ years. The male to female ratio was 1.8:1. While the urinary bladder was the commonest site of the stone amongst our patients $(\mathrm{n}=37,48.7 \%), 4$ (5.3\%) were found at multiple sites. All the patients had abdominal ultrasound and $57.9 \%$ had, in addition, a computerized tomography (CT) urography. Majority, (53.9\%) were treated by open surgery. There was no statistically significant impact of gender on disease presentation $(P=0.167)$ or treatment $(P=0.8381)$. However the patients who had surgical treatment were significantly older than those who were treated conservatively $(P=0.033)$. Conclusion: Urolithiasis in our region has become more common, mimicking the increasing prevalence reported in the West. Most of the cases of urinary tract stones are still successfully managed by open surgery and thus open stone surgery should be considered as a valid alternative to endourologic management techniques in resource poor regions lacking endoscopic facilities.
\end{abstract}

Keywords: Urolithiasis, Nigeria, Open Surgery

\section{Introduction}

Urolithiasis or stone in the urinary tract has afflicted humans since centuries dating back to 4000BC [1], with the disease prevalence varying widely from one part of the world to another. The prevalence is estimated to be $1-5 \%$ globally, $2-13 \%$ in developed countries and $0.5-1 \%$ in developing nations $[2,3]$.

Contrary to earlier studies that depicted urinary stone disease as being rare in Nigeria [4-6], a number of recent reports have shown an increasing incidence [7-12]. Although the reasons for this change in incidence rates remain speculative, rising socioeconomic development and climatic change in the Sub-Saharan nations have been advanced as possible causes [13]. As one of the biggest economies in Africa, more Nigerians have shifted from traditional African diets which were agro-based to the rather additives-laden and processed western diet. Also, there have been suggestions of temperature increases during hot seasons. In addition, improved availability of modern diagnostic tools and trained personnel have made the disease more easily detectable $[13,14]$.

The options of treatment of urolithiasis that have been described include watchful waiting, stone dissolution, 
medical expulsive therapy, extracorporeal treatment, endoscopic interventions with lithotripsy and open surgery. The specific mode of treatment will depend on the site, size and number of stones, patient's clinical condition and in resource poor settings also on the hospital's capability for uroendoscopic procedures. Though a number of private hospitals are beginning to acquire equipment for minimally invasive surgery, most public health facilities in Nigeria still offer only open surgeries for urinary tract stones.

In this study, we aim to document the pattern and management of urinary calculi disease seen at the Lagos State University Teaching Hospital, Ikeja.

\section{Patients and Methods}

We retrospectively reviewed the cases of urolithiasis managed at the Lagos State University Teaching Hospital, Ikeja between January 2012 and December 2016. The patients' clinical records were retrieved from the surgical emergency unit, urology clinics and wards. Information obtained included patients' age, gender, occupation, dietary and social habits as well as presenting symptoms, radiological findings (location and number of stones), laboratory/urinalysis findings and treatment modality.

The data were expressed as means and medians, and analysis was by Statistical Package for Social Sciences (SPSS) version 20.0 for windows. Tests for statistical significance were carried out using the Fischer's exact and Chi square test, with a $P$ value $<0.05$ considered significant.

\section{Results}

The full records of a total of seventy-six patients who were treated for urinary stone disease within the 5-year study period were available for review. Their ages ranged from 2 years to 84 years with a mean age of $49.13 \pm 16.27$ years. The median age was 50.5 years while modal class was the $6^{\text {th }}$ decade [Figure 1].

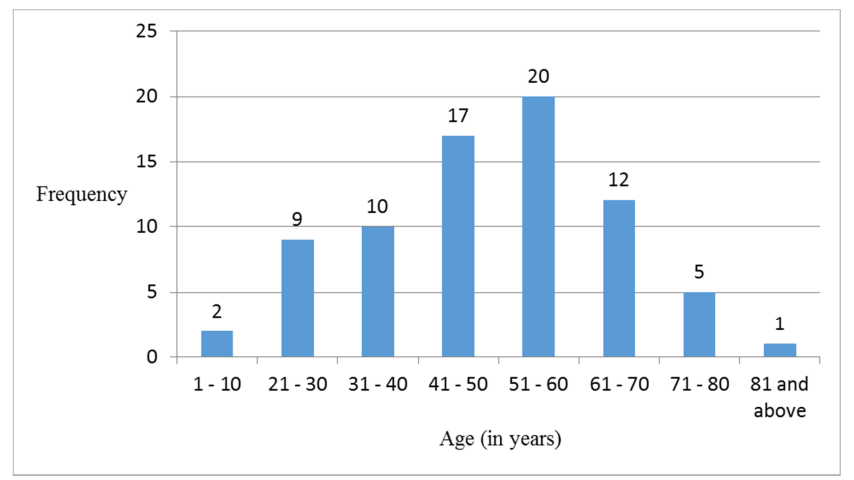

Figure 1. Age Distribution of the patients.

There were $49(64.5 \%)$ males and 27 (35.5\%) females, with a male: female ratio of $1.8: 1$. The presenting symptoms were as detailed in [Figure 2]. The most common symptom was flank pain in $36.8 \%(n=28)$ of the patients.

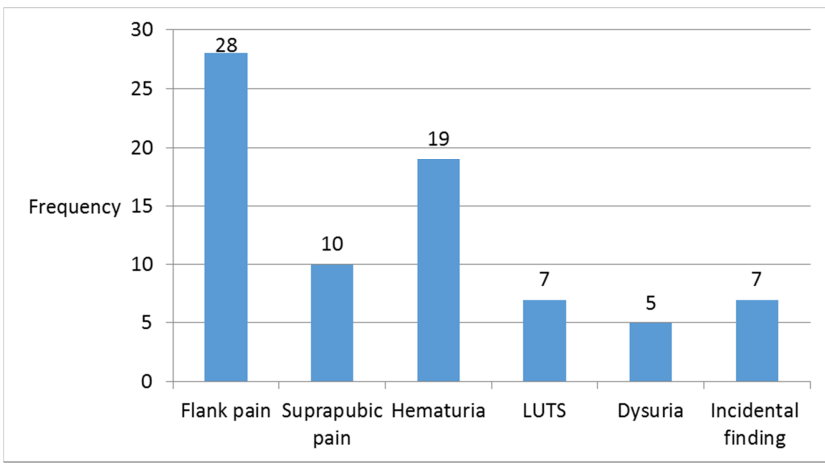

Figure 2. Presenting complaints.

Figure 3 depicts the various locations of the calculi in the urinary tract. While urinary bladder was the commonest site of the stone amongst our patients $(n=37,48.7 \%), 4(5.3 \%)$ were found at multiple sites.

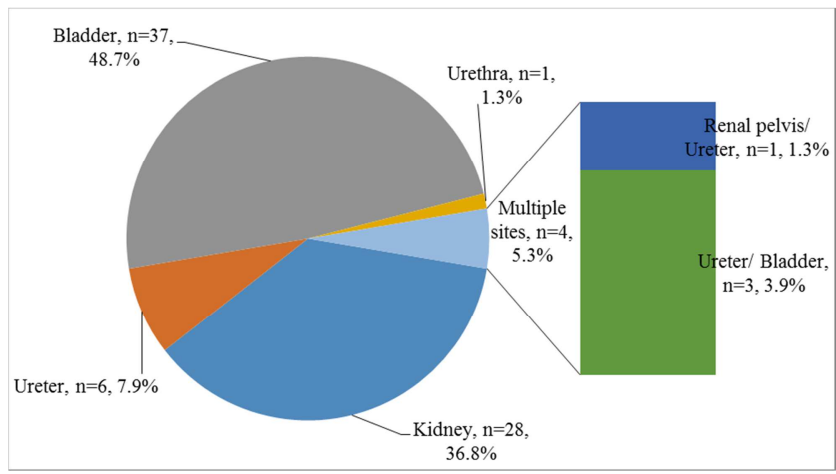

Figure 3. Site of stone.

Of the 38 patients with upper urinary tract (kidneys and ureters) calculi, $57.9 \%(\mathrm{n}=22)$ were on the right side and $34.2 \%(n=13)$ were on the left, while $7.9 \%(n=3)$ had bilateral calculi.

Twenty-six $(34.2 \%)$ out of the 76 patients had hematuria while only $22.4 \%(n=17)$ had crystals on urinalysis. All our patients had Abdominal Ultrasonography done and 57.9\% $(n=44)$ had in addition, Computerized Tomography (CT) urography done.

Open surgery was the most common modality of treatment used in the management our patients (Figure 4).

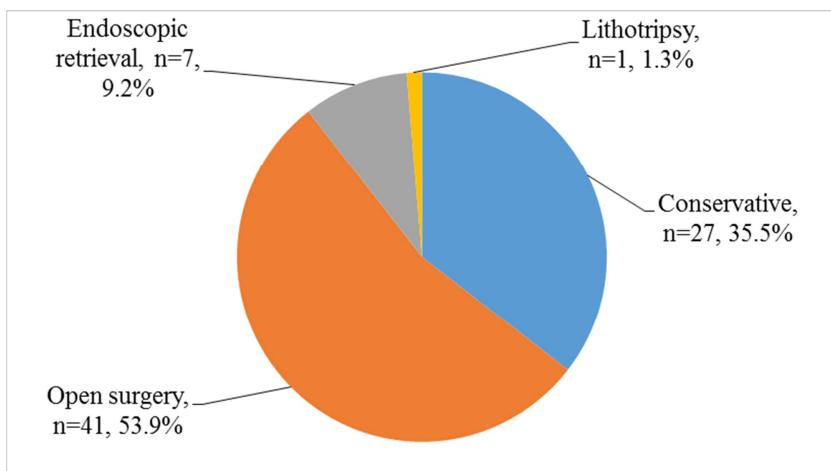

Figure 4. Treatment Approach.

Only one patient $(1.3 \%)$ had a significant urine leak which 
persisted for 6 weeks before it closed up.

There was no mortality.

There was no statistically significant impact of gender on the number of stones $(P=0.167)$ or the need for treatment $(P=0.8381)$, Table 1 and Table 2 .

Table 1. Gender distribution of the patients.

\begin{tabular}{|c|c|c|c|c|}
\hline & & Male & Female & Inference \\
\hline Age & Mean \pm SD & $50.8 \pm 18.0$ & $46.1 \pm 12.2$ & $\mathrm{p}=0.183$ \\
\hline Number of stones & Mean \pm SD & $1.31 \pm 0.55$ & $1.48 \pm 0.51$ & $\mathrm{p}=0.167$ \\
\hline \multirow{2}{*}{ Urinalysis with hematuria } & Positive & 18 & 8 & $\chi^{2}=0.390$ \\
\hline & Negative & 31 & 19 & $\mathrm{p}=0.532$ \\
\hline \multirow{2}{*}{ Need for treatment } & Conservative & 17 & 10 & $\chi^{2}=0.0417$ \\
\hline & Intervention & 32 & 17 & $\mathrm{p}=0.8381$ \\
\hline Form of intervention & Open & 26 & 15 & $\chi^{2}=0.3965$ \\
\hline \multirow{2}{*}{ Laterality } & Right & 16 & 9 & $\chi^{2}=1.6244$ \\
\hline & Left & 7 & 9 & $\mathrm{p}=0.2025$ \\
\hline
\end{tabular}

Table 2. Factors associated with different forms of intervention.

\begin{tabular}{|c|c|c|c|c|c|}
\hline $\mathbf{S} / \mathbf{N}$ & Factors & & Conservative $(n=27)$ & Intervention $(n=49)$ & Test of significance \\
\hline 1 & Age (in years) & & $43.4 \pm 18.08$ & $52.9 \pm 14.42$ & $\begin{array}{l}\mathrm{t}=2.196 \\
\mathrm{p}=0.033\end{array}$ \\
\hline \multirow{2}{*}{2} & \multirow{2}{*}{ Gender } & Male & 17 & 32 & $\chi^{2}=0.0417$ \\
\hline & & Female & 10 & 17 & $\mathrm{p}=0.8381$ \\
\hline 3 & \multicolumn{2}{|l|}{ Number of stones } & $1.41 \pm 0.57$ & $1.35 \pm 0.52$ & $\begin{array}{l}t=-0.454 \\
p=0.651\end{array}$ \\
\hline 4 & Number of stones & 1 & 17 & 33 & $\chi^{2}=0.149$ \\
\hline \multirow{3}{*}{5} & \multirow{3}{*}{$\begin{array}{l}\text { Exact number of } \\
\text { stones }\end{array}$} & 1 & 17 & 33 & $\mathrm{~F}=0.625$ \\
\hline & & 2 & 9 & 15 & \multirow{2}{*}{$\mathrm{p}=0.907$} \\
\hline & & 3 & 1 & 1 & \\
\hline
\end{tabular}

The patients who had surgical intervention for treatment were however significantly older than the patients who had conservative treatment $(P=0.033)$. Table 2

\section{Discussion}

Recent reports have shown an increasing incidence of urolithiasis in Nigeria, [7, 8, 12], similar to the data from the Western world and the Middle East. [1, 15-17] Different factors have been suggested to explain this changing pattern in our region viz; improving socioeconomic indices and climatic change $[13,18]$. Added to these are improvements in modern investigation tools as well as improved capacity of trained personnel in making diagnosis of urinary stone disease.

In our study, we found urolithiasis in all age groups, corroborating the findings in other researches which suggested that urinary stone disease is no respecter of age [3, $19,20]$.

It has been documented that male predominance has been on the decline over the recent years [21]. We recorded a male: female of 1.8:1.

Globally, upper urinary tract stones are more common in contrast to the picture in developing countries where preponderance of lower tract calculi is documented [5, 22]. We found the urinary bladder as the commonest site of urinary calculi in our patients. This finding is similar to the recent report by Abubakar et al. [23] These calculi may be attributed to complications of poorly managed bladder outlet obstruction leading to stasis and infection. Some workers have argued for the possible role of urinary tract infections in the formation of uroliths in Nigerians. [24]

All our patients had abdominal ultrasonography. Ultrasound is usually the primary investigation of choice in urinary stone disease. It is easily accessible and affordable with no risk of radiation. It has a sensitivity of $45 \%$ and specificity $>85 \%$ for nephrolithiasis and ureterolithiasis [25]. Indeed some of the bladder stones were incidental findings on ultrasound. In addition to the abdominal ultrasound, $57.9 \%$ of the cases we treated had a CT Urography done. Apart from giving detailed information about abdominal pain in the absence of calculi [26], non-contrast CT has a sensitivity of $100 \%$ and specificity of $>94 \%$ for urinary calculi $>3 \mathrm{~mm}$ except with indinavir stone [27]. A CT Urography was always the investigation of choice in our patients with suspected ureteric stones in particular.

A considerable number of our patients were managed conservatively $(35 \%, n=27)$. They expelled their stones spontaneously after 3-4 weeks on oral Tamsulosin and proper hydration. These were mainly the patients with stones $\leq 4 \mathrm{~mm}$ in size. Tamsulosin is a selective alpha - blocker and is a known agent for medical expulsive therapy [28]. Studies have shown that spontaneous passage of stone depends on the size of the calculus and its actual site in the ureter [2931]. Most of the patients in our study were however treated by open surgery. These were mostly large vesical, large renal pelvic and staghorn renal calculi which were removed during open cystolithotomies (as well as prostatectomies sometimes), pyelolithotomies and nephrolithotomies respectively. Few patients had endoscopic stone retrieval $(n=7,9.2 \%)$ at cystoscopy for small bladder calculi and 
stones impacted at the vesicoureteric junction. The single patient who had lithrotripsy $(n=1,1.3 \%)$ for a distal ureteric stone had the surgery done as a demonstration surgery which was carried out in our institution. Flexible ureteroscope, percutaneous nephrolithotomy (PCNL) set and laser equipment are unavailable in most public health institutions in Nigeria, including ours.

There was no impact of gender on the pattern of presentation or treatment modality. The significantly higher incidence of surgical intervention with increased age that we found was probably due to the high incidence of elderly patients with huge bladder stones and bladder outlet obstruction. Further studies will be needed to clarify the significance of this finding. Though most of the surgeries were open, the outcome was very good and to patients' satisfaction with no mortality or significant morbidity.

The global trend in the management of urolithiasis is now towards one form of minimally invasive procedure or the other and this should be the aspiration of medical centres in developing countries. However the appropriate selection of stone removal therapies will continue to require further investigations [32]. Some authors have indeed documented that some of these minimally invasive treatment options for urolithiasis may actually not be cost effective for patients and hospital management in some resource poor regions like Nigeria. [33] When safely done, open stone surgery still holds a strong position in the management of urolithiasis especially for complicated cases and complex stone burden. [34]

\section{Conclusion}

Urolithiasis in our region has become more common, mimicking the increasing prevalence reported in the West although we still have preponderance of the calculi in the lower urinary tract. Most of the cases of urinary tract stones are still successfully managed by open surgery. Though investment in minimal access equipment and skill should be encouraged, open surgery for urinary tract stone remains a safe and valid alternative to endourologic management techniques in most situations in resource poor regions.

\section{References}

[1] López M, Hoppe B. History, epidemiology and regional diversities of urolithiasis. Pediatr Nephrol 2010; 25: 49-59.

[2] Victoriano Romero, Kidney stones: A global picture of prevalence, incidence and associated risk factor. Review in Urology. 2010; 12 (2-3): e86-e96.

[3] Sharma AP, Filler G. Epidemiology of pediatric urolithiasis. Indian J Urol 2010; 26: 516-22.

[4] Esho JO. Experience with urinary calculus disease in Nigerians as seen at the Lagos University Teaching Hospital. Niger Med J 1976; 6: 18-22.

[5] Mbonu O, Attah C, Ikeakor I. Urolithiasis in an African population. Int Urol Nephrol 1984; 16: 291-6.

[6] Monu JU. Pattern of urolithiasis in Benin City, Nigeria. J Natl Med Assoc 1989; 81: 695-8.

[7] Osegbe DN. The rise in urolithiasis in Nigeria. Br Med J (Clin Res Ed) 1987; 295: 1654.

[8] Aji SA, Alhassan SU, Mohammed AM, Mashi SA. Urinary stone disease in Kano North Western Nigeria. Niger Med J 2011; 52: 83-5.

[9] Ekwere PD. Urinary calculous disease in South-Eastern Nigeria. Afr J Med Med Sci 1995; 24: 289-95.

[10] Emokpae MA, Gadzama AA. Anatomical distribution and biochemical composition of urolithiasis in Kano, Northern Nigeria. Int J Biol Chem Sci 2012; 6: 1158-66.

[11] Mshelia DS, Gali BM, Naaya UH, Habu SA. Chemical composition of urinary calculi in Maiduguri, Nigeria. Afr J Med Med Sci 2005; 34: 185-8.

[12] Adetayo FO, Saanu OO, Osegbe DN. Chemical composition of urinary calculi in Nigerians. Nig Q J Hosp Med 2004; 14: 143-6.

[13] Ansari MS, Gupta NP. Impact of socioeconomic status in etiology and management of urinary stone disease. Urol Int 2003; 70: 255-61.

[14] Vermooten V. Occurrence of renal calculi and their possible relation to diet as illustrated in South African Negroes. JAMA 1937; 109: 857.

[15] Romero V, Akpinar H, Assimos DG. Kidney stones: A global picture of prevalence, incidence, and associated risk factors. Rev Urol 2010; 12: e86-96.

[16] Soucie JM, Thun MJ, Coates RJ, McClellan W, Austin H. Demographic and geographic variability of kidney stones in the United States. Kidney Int 1994; 46: 893-9.

[17] Khan AS, Rai ME, Gandapur, Pervaiz A, Shah AH, Hussain AA, et al. Epidemiological risk factors and composition of urinary stones in Riyadh Saudi Arabia. J Ayub Med Coll Abbottabad 2004; 16: 56-8.

[18] Beukes GJ, de Bruiyn H, Vermaak WJ. Effect of changes in epidemiological factors on the composition and racial distribution of renal calculi. Br J Urol 1987; 60: 387-92.

[19] Sas DJ, Hulsey TC, Shatat IF, Orak JK. Increasing incidence of kidney stones in children evaluated in the emergency department. J Pediatr 2010; 157: 132-7.

[20] Sternberg K, Greenfield SP, Williot P, Wan J. Pediatric stone disease: An evolving experience. J Urol. 2005; 174: 1711-4.

[21] Hesse AT (2009) Urinary Stones, Diagnosis, Treatment and Prevention of Recurrence. (3rd Edition). 2009, Basel, Switzerland.

[22] Rahman GA, Akande AA, Mamudu NA. Giant vescical calculi: experience with management of two Nigerians. Nig J Surg. 2005; 7: 203-5.

[23] Abubakar BM, Abubakar A, Suleiman IE, Makama BS, Abdulhafeez AA, Gashua MG. Pattern of Presentation and Management of Urolithiasis at Federal Medical Centre, Nguru, Nigeria. Bo Med J 2017; 14: (1) 63-70. 
[24] Meka IA, Ugonabo MC, Ebede SO, Agbo EO. Composition of uroliths in a tertiary hospital in South East Nigeria. Afri Health Sci. 2018; $18 \quad$ (2): $437-445$ https://dx.doi.org/10.4314/ahs.v18i2.29.

[25] Ghiculete D, Pace KT, Honey RJ. Limitations to ultrasound in the detection and measurement of urinary tract calculi. Urology 2010; 76: 295.

[26] Heidenreich A, Desgrandschamps F, Terrier F. Modern approach of diagnosis and management of acute flank pain: review of all imaging modalities. Eur Urol. 2002; 41: 351.

[27] Smith Bindman R, Chandra Aubin, John Bailitz, Rimon N Bengiamin, Carlos A Camargo, et al. Ultrasonography versus computed tomography for suspected nephrolithiasis. N Engl J Med. 2014; 371: 1100 .

[28] Pickard R, K Starr, G Maclennan, Thomas Lam, Ruth Thomas, et al. Medical expulsive therapy in adults with ureteric colic: a multicentre, randomised, placebo-controlled trial. Lancet 2015; 386: 341.

[29] Ahmed AF, Gabr AH, Emara AA, Ali M, Abdel-Aziz AS, Alshahrani S. Factors predicting the spontaneous passage of a ureteric calculus of $\leq 10 \mathrm{~mm}$. Arab J Urol 2015; 13: 84-90.
[30] Singh A, Alter HJ, Littlepage A. A systematic review of medical therapy to facilitate passage of ureteral calculi. Ann Emerg Med 2007; 50: 552-63.

[31] Arain YS, Ali SA, Miraj M, Siddigwi AJ. Lower ureteral calculi, a bothering problem; is there any non-invasive therapy to get rid of them? Role of tamsulosin. J Med Sci 2014; 5: 3740 .

[32] Raheem OA, Khandwala YS, Sur RL, Ghani KR, Denstedt JD. Burden of Urolithiasis: Trends in Prevalence, Treatments, and Costs. European Urology Focus. 2017; 3 (1): 18-26.

[33] Eze KC, Irekpita E, Salami TA. Cost-effectiveness of extracorporeal shock wave lithotripsy in a poor resource setting: The Okada, Nigeria experience. Niger Med J. 2016 Jan-Feb; 57 (1): 44-48.

[34] Cakici OU, Ener K, Keske M, Altinova S, Canda AE, Aldemir M, Ardicoglu A. Open stone surgery: a still-in-use approach for complex stone burden. Cent European J Urol. 2017 Jun 30; 70 (2): 179-184. 